\title{
INFECTION CONTROL PRACTICES IN PESHAWAR
}

\author{
Faisal Saeed ${ }^{1}$, Afaq Farooq ${ }^{2}$, Farooq Maqsood ${ }^{3}$, Kamran Khan $^{4}$, Ihtisham Ali ${ }^{5}$, \\ Mohammad Sartaj ${ }^{6}$
}

\section{ABSTRACT:}

\section{OBJECTIVES:}

The purpose of this study was to assess the infection control practices among dental trainees and house-officers. The use of method of sterilization, to figure out that whether the dental trainees are vaccinated against Human ImmunoDeficiency Virus (HIV), Acquired Immuno-Deficiency Syndrome (AIDS), Hepatitis $B$ and $C$, the color-coded waste segregation protocols implementation in dental hospitals.

\section{METHODOLOGY:}

A comparative study was conducted in Sardar Begum Dental Hospital (SBDH), Peshawar. The total number of the participants was 150 dental practitioners (75 training medical officers and 75 house officers) including both genders from different departments of SBDH. A questionnaire was designed to obtain the data on infection control practices, method using for sterilization, vaccination of the trainees and waste segregation protocols. The collected data were analyzed using SPSS 21.0 .

\section{RESULTS:}

Training medical officers (TMO) and house-officers (HO) are following the infection control practices in dental units $(p<0.01)$. The autoclave methods are preferred for sterilization in dental hospital by both trainees ( $p$-value<0.01). Furthermore, TMO's were vaccinated as compared to the HO's. Similarly, the TMO's were more following the color-coded waste disposal protocols.

\section{CONCLUSION:}

Despite the information and practices of infection control there is a need for further developments in this area. The authorities should monitor the infection control practices and vaccinations of the trainees and arrange seminars or workshops for them.

KEYWORDS: Equipment, Disinfectant, Human Immunodeficiency Virus (HIV), Acquired Immunodeficiency Syndrome (AIDS), Sterilization

How to cite this article:

Saeed F, Farooq A, Maqsood F, Khan K, Ali I, Sartaj M. Infection control practices in Peshawar. J Gandhara Med Dent Sci. 2020;6(2):16-21. doi: 10.37762/jgmds.6-2.94 


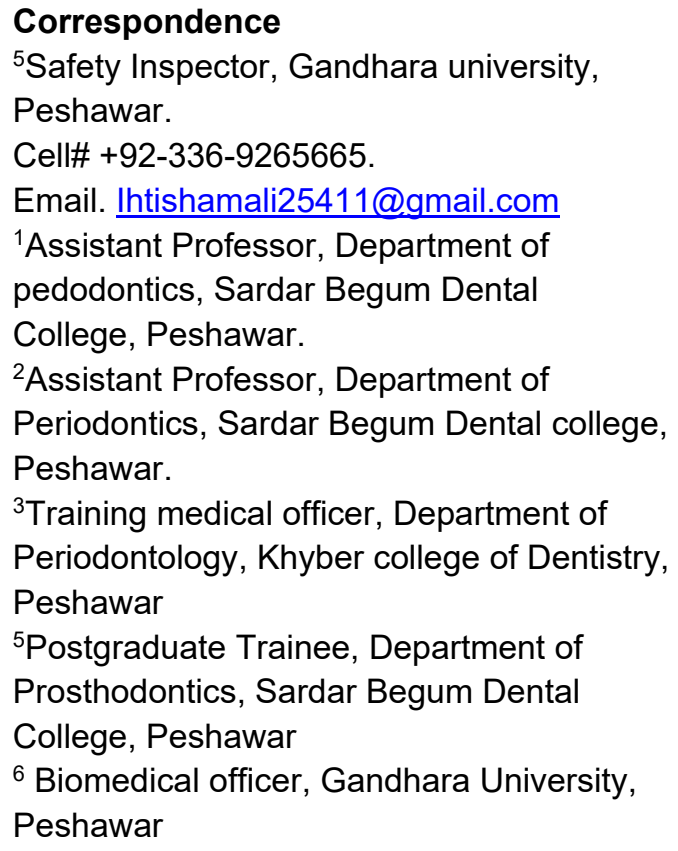

\section{INTRODUCTION:}

Infection control is the sub-discipline of epidemiology which are precautionary measures used in hospitals for the prevention of diseases. It emphasized on the facts that lead to infections in health providing centres either patient to doctor or vice versa ${ }^{1}$. The knowledge and skills are given to the medical students in undergraduate level and they are obliged to upgrade them in order to identify, control and treat the illness cause by infections. Dentists are generally more prone to infectious items such as equipment's, contaminated supplies and body substances $^{2}$. The Centres for Disease Control and Prevention $(C D C)^{3}$ given recommendations for the dental centres. The health professionals especially dentists must care and work for the safety and prevention of diseases. The safety measure can consist of examination of clinical setting (room, chair, lights, handles) to be decontaminated and use disposable covers for patients. Sterilization of dental tools must be implemented for each patients and precautionary steps taken for selfprotection from infections ${ }^{4}$. Dentists are exposed to infectious pathogens; therefore, personal protection procedures are most important in dental clinics to avoid transmission of infectious diseases ${ }^{5}$. The prevention process comprises of hand washing, using personal protective equipment, disinfection and sterilization, vaccinations and waste segregation process. CDC issued guidelines in $2003^{6}$, regarding sterilization of patient care equipment. Sterilization is the process of killing and removing microorganisms that can lead to infectious diseases. Sterilization can be achieved through autoclave method and disinfectants ${ }^{7}$. These are the commonly used methods. In disinfection method microorganisms cannot be completely removed, while autoclave method of sterilization almost kills all the micro-organisms ${ }^{8}$. The infective viruses i.e. HIVIAIDS and hepatitis $\mathrm{B} / \mathrm{C}$ can be transmitted from infected to non-infected individual through surgical instruments ${ }^{9}$. They emphasized on the precautionary measures after the incidence of American dentist, five of his patients got infected with human immunodeficiency virus (HIV) transmitted from him $^{10}$. It's the responsibility of professionals to work 
on the protocols and taking crucial steps for the health of patients ${ }^{11}$. The professional organizations now recommend the use of universal precautions for the control of infections. The American council reported the increasing compliance with recommended infection control over time ${ }^{12}$. In hospital, wastes are generated which has the potential of spreading infections. Therefore, to ensure the safety of patient and dental health care provider, proper management of hospital waste is required. As in compliance with the waste management rules 2005, under Environmental Protection Act 1997 of Government of Pakistan, the hospital is responsible for the management of waste from its generation till its final disposal $^{13}$. Proper waste management means segregation, collection, storage, transportation and disposal of waste in proper way to maintain the hospital environment hygiene. The purpose of this study was to find out the different aspects required for infection control in dental hospital as the dentists as well as patients who seek dental treatments are at higher risk of infectious diseases.

\section{METHODOLOGY:}

It was a comparative study conducted between August and October 2019 in Sardar Begum Dental Hospital. Systematic sampling technique was used for data collection. A list of trainees was taken from the departments and was selected on alternated basis. A self-administered questionnaire was developed, including 20 items to asses infection control practices, methods use for sterilization, vaccination of dental trainees against HIVIAIDS and hepatitis $B / C$ and management of waste disposal. Pre-testing of questionnaire was done on $10 \%$ of the population. The study sample consists of 150 dental trainees including training medical officers $(n=75)$ and house officers $(n=75)$. The other faculty members and senior doctors were excluded. This questionnaire was distributed manually to carry out study. Inform consent was taken from the authorities and participants. The approval for conducting this study was taken from the ethical committee of Gandhara University. Statistical analysis was performed using SPSS 21.0. Chi-square test was used for analysis of data and presentation of results.

\section{RESULTS:}

In this study, Table 1 results show percentages of infection control practices among medical trainees $(p<0.01)$. In Table 2, both dental trainees were mostly using autoclave methods for sterilization. In Table 3, maximum training medical officers were vaccinated as compared to house officers. In Table 4, the results revealed that TMO's have knowledge and they are using color-coded bins protocols whereas the HO's response was minimum. 
Table 1: Infection Control Practices

\begin{tabular}{|l|c|c|c|c|c|}
\hline & Yes & No & Total & Chi-Square & P-value \\
\hline House Officers & $45(60.0 \%)$ & $30(40.0 \%)$ & $75(100 \%)$ & 10.71 & $<0.01$ \\
\cline { 1 - 4 } $\begin{array}{l}\text { Training Medical } \\
\text { Officers }\end{array}$ & $50(66.7 \%)$ & $25(33.3 \%)$ & $75(100 \%)$ & & \\
\hline
\end{tabular}

Table 2: Methods of Sterilization

\begin{tabular}{|l|c|c|c|c|c|}
\hline & Autoclave & Disinfection & Total & Chi-Square & P-value \\
\hline House Officers & $70(93.3 \%)$ & $5(6.7 \%)$ & $75(100 \%)$ & 5.76 & $<0.01$ \\
\cline { 1 - 4 } $\begin{array}{l}\text { Training Medical } \\
\text { Officers }\end{array}$ & $60(80.0 \%)$ & $15(20.0 \%)$ & $75(100 \%)$ & & \\
\hline
\end{tabular}

Table 3: Vaccination Against Hepatitis B/C and HIVIAIDS

\begin{tabular}{|l|c|c|c|c|c|}
\hline & Yes & No & Total & Chi-Square & P-value \\
\cline { 1 - 4 } $\begin{array}{l}\text { Training Medical } \\
\text { Officers }\end{array}$ & $70(93.3 \%)$ & $5(6.7 \%)$ & $75(100 \%)$ & 48.00 & $<0.001$ \\
\cline { 1 - 3 } Houfficers & $30(40.0 \%)$ & $45(60.0 \%)$ & $75(100 \%)$ & & \\
\hline
\end{tabular}

Table 4: Hospital Waste Segregation (Color Coded Bins)

\begin{tabular}{|l|c|c|c|c|c|}
\hline & Yes & No & Total & Chi-Square & P-value \\
\cline { 1 - 4 } $\begin{array}{l}\text { Training Medical } \\
\text { Officers }\end{array}$ & $72(96.0 \%)$ & $3(4.0 \%)$ & $75(100 \%)$ & 26.85 & $<0.001$ \\
\cline { 1 - 4 } House Officers & $46(61.3 \%)$ & $29(38.7 \%)$ & $75(100 \%)$ & & \\
\hline
\end{tabular}

\section{DISCUSSION:}

According to the study conducted in Tennessee State of U.S, the dental hospital environment is exposed to significant number of risks to microorganisms and its various diseases $^{14}$. Regarding viral infections there are many microorganisms, which are present in the blood and saliva of the patients ${ }^{6}$. Therefore, the procedures for the control of infection are necessary to be followed. According to our study majority of the Training Medical Officers (66\%) are following infection control practices as compared to House Officers (40\%). Sterilization is the most safe and essential process for sterilizing the reusable dental instruments, because it kills the microorganisms, which is the direct source of spreading the infections from patient to patient and from patient to the dental health care provider ${ }^{15}$. There are various methods for sterilization, but most safe and efficient way of sterilization is the autoclave method of sterilization in dental settings. Most of the dental trainees (house officers-93.3\% and trainee medical officers- $80 \%$ ) are using the autoclave method of sterilization. The association for professionals in infection control and epidemiology support the prevention of infection control through immunization. There are institutes that provide immunization schedules to vaccinate their students and staff from viral diseases and infections from their routine practices ${ }^{16}$. The result shows that at Sardar Begum Dental Hospital, $93 \%$ of trainee 
medical officers and $40 \%$ of the house officers are vaccinated against HIVIAIDS and Hepatitis B/C. The surveys conducted in Minnesota ${ }^{17}$, showed that the infection control practices are increasing in dentists and post-graduate trainees had higher vaccination rates and use of regular techniques. A study conducted in Lahore, regarding infectious waste management, proper waste management play an important role in infection control inside a health care institution, and therefore segregation of waste in a proper way is necessary ${ }^{18}$. According to our study in Sardar Begum Dental College, $96 \%$ of the trainee medical officers and $61.3 \%$ of house officers are following protocols for waste segregation.

\section{CONCLUSION:}

This study shows that fresh dental trainees $(\mathrm{HO})$ are relatively feeble in following the precautionary measures for infection control. There is inadequacy of vaccinations against HIVIAIDS and hepatitis B/C among them. It is recommended that there should be compliance in infection control measures. At institutional level, there should be workshops to improve the knowledge and skills of the dentists.

\section{LIMITATIONS:}

The sample was collected from one dental hospital of Peshawar. There is need to conduct such studies on provincial level and select dental trainees from other public and private dental hospitals as well.

\section{REFERENCES:}

1. Babar FR. Knowledge, attitude and practice regarding Hepatitis B \& C among dental surgeons of Khyber College of Dentistry (KCD) Peshawar and Bolan Medical College (BMC) Quetta. Biomed J Sci Tech Res. 2017;1(6):1569-73.

2. Yüzbasioglu $E$, Saraç $D$, Canbaz $S$, Saraç YS, Cengiz S. A survey of cross-infection control procedures: knowledge and attitudes of Turkish dentists. J Appl Oral Sci. 2009;17(6):565-9.

3. Kohn WG, Harte JA, Malvitz DM, Collins AS, Cleveland JL, Eklund KJ. Cover story guidelines for infection control in dental health care settings2003. J Am Dent Assoc. 2004;135(1):33-47.

4. de Amorim-Finzi MB, Cury MV, Costa CR, dos Santos AC, de Melo GB. Rate of compliance with hand hygiene by dental healthcare personnel (DHCP) within a dentistry healthcare first aid facility. Eur $\mathrm{J}$ Dent. 2010;4(3):233-7.

5. Mohiuddin S, Dawani N. Knowledge, attitude and practice of infection control measures among dental practitioners in public setup of Karachi, Pakistan: cross-sectional survey. J Dow Uni Health Sci. 2015;9(1):89-93.

6. Henderson DK. Managing occupational risks for hepatitis C transmission in the health care setting. Clin Microbiol Rev. 2003;16(3):546-68.

7. Kelsch N, Davis CA, Essex G, Laughter L, Rowe DJ. Effects of mandatory continuing education related to infection control on the infection control practices of dental hygienists. Am J Infection Control. 2017;45(8):926-8. 
8. Rutala WA, Weber DJ. Disinfection and sterilization in health care facilities: what clinicians need to know. Clin Infectious Diseases. 2004;39(5):702-9.

9. Laheij AM, Kistler JO, Belibasakis GN, Valimaa $\mathrm{H}$, de Soet JJ. Healthcare-associated viral and bacterial infections in dentistry. J Oral Microbiol. 2012; 4:1-10.

10. Centers for Disease Control (CDC). Update: transmission of HIV infection during invasive dental proceduresFlorida. MMWR Morb Mortal Wkly Rep. 1991;40(23):377-81.

11. Dagher J, Sfeir C, Abdallah A, Majzoub Z. Infection control measures in private dental clinics in Lebanon. Int J Dent. 2017; 5057248:1-11.

12. World Health Organization (WHO). World Health Organization Hepatitis C: Fact Sheet 164. 2015.

13. Arshad N, Nayyar S, Amin F, Mahmood KT. Hospital waste disposal: a review article. J Pharm Sci Res. 2011;3(8):1412-9.
14. Mehboob B, Khan M, ud-Din F, Khan AA, Qiam F. Professional hazards among dentists of the two public sector teaching hospitals of Khyber Pakhtunkhwa province of Pakistan. Pak Oral Dent J. 2012;32(3):376-80.

15. Alam M, Behttani F. Prevalence of risk factors in hepatitis $B$ \& C patients admitted in eye department of Khyber Teaching Hospital, Peshawar. Ophthalmology. 2011;9(4):39-41.

16. Smith AJ, Bagg J, Hurrell D, McHugh S. Sterilisation of re-usable instruments in general dental practice. Br Dent J. 2007;203(8): E16.

17. DiAngelis AJ, Martens LV, Little JW, Hastreiter RJ. Infection control practices of Minnesota dentists: changes during 1 year. J Am Dent Assoc. 1989;118(3):299-303.

18. Mushtaq A, Alam $M$, lqbal $S$, Mushtaq S. Management of dental waste in a dental hospital of Lahore. Biomedica. 2008; 24:613.

\section{CONTRIBUTORS}

1. Faisal Saeed - Data Analysis/Interpretation; Critical Revision; Supervision; Final Approval

2. Afaq Farooq - Drafting Manuscript; Critical Revision; Supervision; Final Approval

3. Farooq Maqsood - Data Acquisition; Data Analysis/Interpretation; Supervision; Final Approval

4. Kamran Khan - Data Acquisition; Data Analysis/Interpretation

5. Ihtisham Ali - Concept \& Design; Data Acquisition; Data Analysis/Interpretation; Drafting Manuscript

6. Mohammad Sartaj - Concept \& Design; Data Acquisition; Drafting Manuscript

LICENSE: JGMDS publishes its articles under a Creative Commons Attribution Non-Commercial Share-Alike license (CC-BY-NC-SA 4.0). COPYRIGHTS: Authors retain the rights without any restrictions to freely download, print, share and disseminate the article for any lawful purpose. It includes scholarly networks such as Research Gate, Google Scholar, LinkedIn, Academia.edu, Twitter, and other academic or professional networking sites. 